\title{
A ABORDAGEM SISTÊMICA E O LEGADO CULTURAL DOS LADRILHOS HIDRÁULICOS NA REGIÃO DE MURIAÉ - Design sistêmico aplicado à sustentabilidade e à pluralidade cultural dos ladrilhos hidráulicos
}

\author{
THE SYSTEMIC APPROACH AND THE CULTURAL LEGACY OF HYDRAULIC TILE IN THE \\ MURIAÉ REGION - Systemic design applied to the sustainability and cultural plurality \\ of hydraulic tiles
}

DE OLIVEIRA, Fernanda T. F.; Bacharel em Design; Instituto de Artes e Design, Universidade Federal de Juiz de Fora.

fernandatavoradesign@gmail.com

MIRANDA DE OLIVERA, Paulo; PhD; Instituto de Artes e Design, Universidade Federal de Juiz de Fora. paulo.miranda@ufjf.edu.br

\begin{abstract}
Resumo
O ladrilho hidráulico é um revestimento resistente, cheio de grafismos e que está presente em monumentos históricos, assim como na memória dos brasileiros. A sua produção é artesanal e culturalmente importante, desse modo sua preservação e identidade é de grande relevância como patrimônio sociocultural. O legado e os desdobramentos das técnicas do ladrilho hidráulico estenderam-se às novas fronteiras, preservando o know-how e criando uma segmentação diferenciada, representada pela joalheria artística, que fomenta o valor através do significado das peças e mantém a cultura e a sabedoria da produção dos ladrilhos. Como resultado desse amplo e rico cenário, regado de história e tradições locais, foram produzidas peças de joalheria artística utilizando as técnicas de produção de ladrilhos hidráulicos, tendo o cimento como principal matériaprima.
\end{abstract}

Palavras Chave: Design sistêmico; ladrilho hidráulico; joias contemporâneas.

\begin{abstract}
The hydraulic tile is a resistant coating, filled with graphics and that is present in historical monuments, as well as in the memory of the Brazilians. Its production is artisanal and culturally important, so its preservation and identity are of great importance as socio-cultural patrimony. The legacy and the unfolding of the techniques of the hydraulic tile, understood the new frontiers, preserving the know-how and creating a differentiated segmentation represented by the artistic jewelry, fomenting the value through the meaning of the pieces, preserving the culture and the wisdom of the production two tiles. As a result of this large and rich scenario, full of history and local traditions, pieces of artistic jewelry were produced using the techniques of producing hydraulic tiles, cement being the main raw material.
\end{abstract}




\section{LADRILHOS HIDRÁULICOS}

Como ponto de partida para o estudo e, posteriormente, aprofundamento deste trabalho, foram realizadas pesquisas e levantamentos bibliográficos específicos ao objetivo desse campo investigativo, deu-se ênfase e proposital atenção às características apresentadas pela fábrica de artefatos hidráulicos ARTE EM LADRILHOS, estabelecida na cidade mineira de Muriaé-MG.

Nesta ênfase percebeu-se a grande história e importância da produção do ladrilho hidráulico no impacto cultural e comercial na produção de revestimentos, principalmente da Zona da Mata, local onde a fábrica está estabelecida a mais de 90 anos. Este ponto levou a percepção da importância com relação a preservação dessa cultura imaterial que é a produção artesanal do ladrilho hidráulico.

Com o objetivo de entender melhor as relações culturais e processuais que estabelecem o cerne do ladrilho hidráulico foram levantados dados históricos que demonstram as origens e os desdobramentos que levaram à invenção do ladrilho hidráulico (Figura 1).

Figura 1 - Comparação entre os mosaicos antigos e os desenhos dos ladrilhos hidráulicos. (A) Túmulo de Hafez , Shiraz, Irã. (B) Ladrilhos Art Nouveau confeitaria colombo Rio.

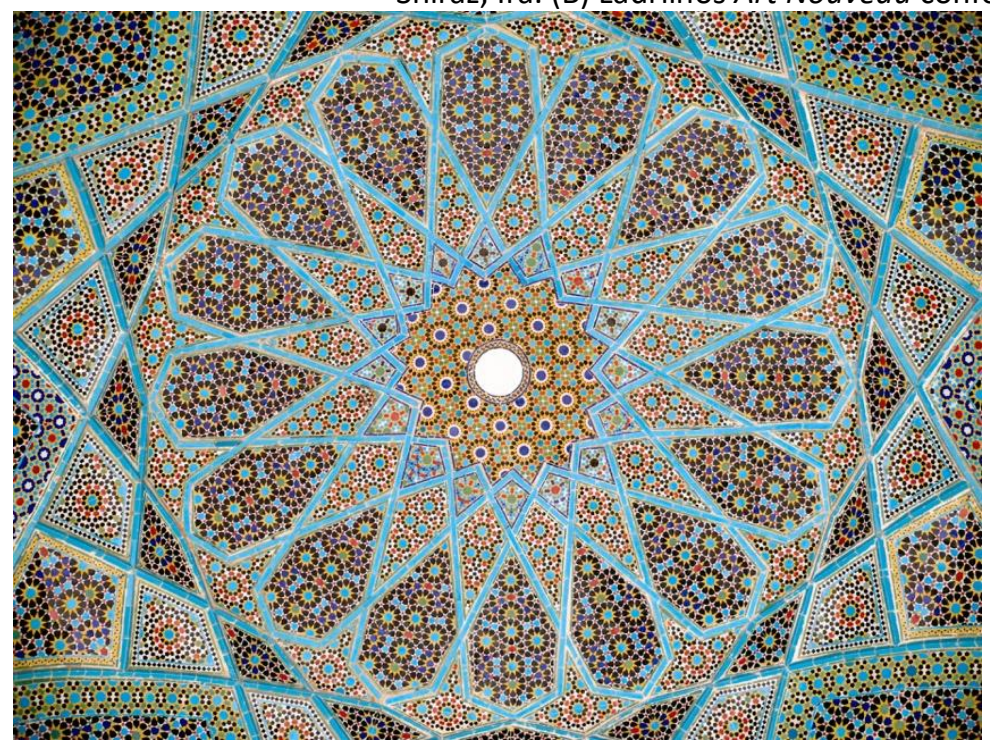

(A)

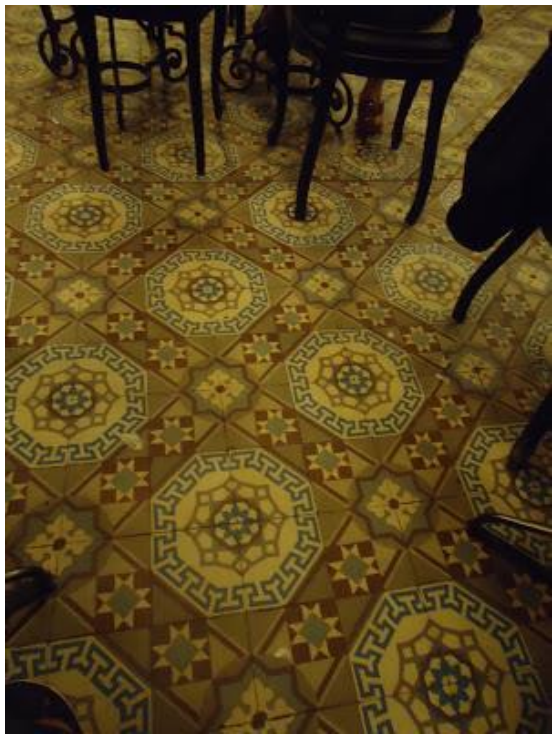

(B)

Fonte: (A) Foto de Wikipedia.org, 2017; (B) Foto de Vai bagagem, 2011.

O que foi percebido é a relação dos ladrilhos hidráulicos como desdobramento tecnológico, a partir da técnica da arte dos mosaicos (CAMPOS, 2011 apud NAVARRO e MORÁN, 2010, p.31), que de acordo com FARTHING (2011), está muito atrelada a representações religiosas ao longo da história.

Entende-se que o processo do ladrilho se baseia no uso do cimento para a produção de um revestimento que não precisa de queima para se tornar resistente, mas sim de água, e por isso seu nome ladrilho hidráulico. Outro elemento fundamental ao processo do ladrilho são seus desenhos intricados, devido sua influência vinda dos mosaicos. Esse elemento é tão importante que foi a partir dele que o processo do ladrilho foi desenvolvido. Para conseguir os desenhos diferenciados dos 
ladrilhos hidráulicos o processo começa no desenvolvimento de moldes em latão, que separam as cores que darão definição ao desenho do revestimento (Figura 2).

Figura 2 - Ladrilho hidráulico e seu molde em latão.

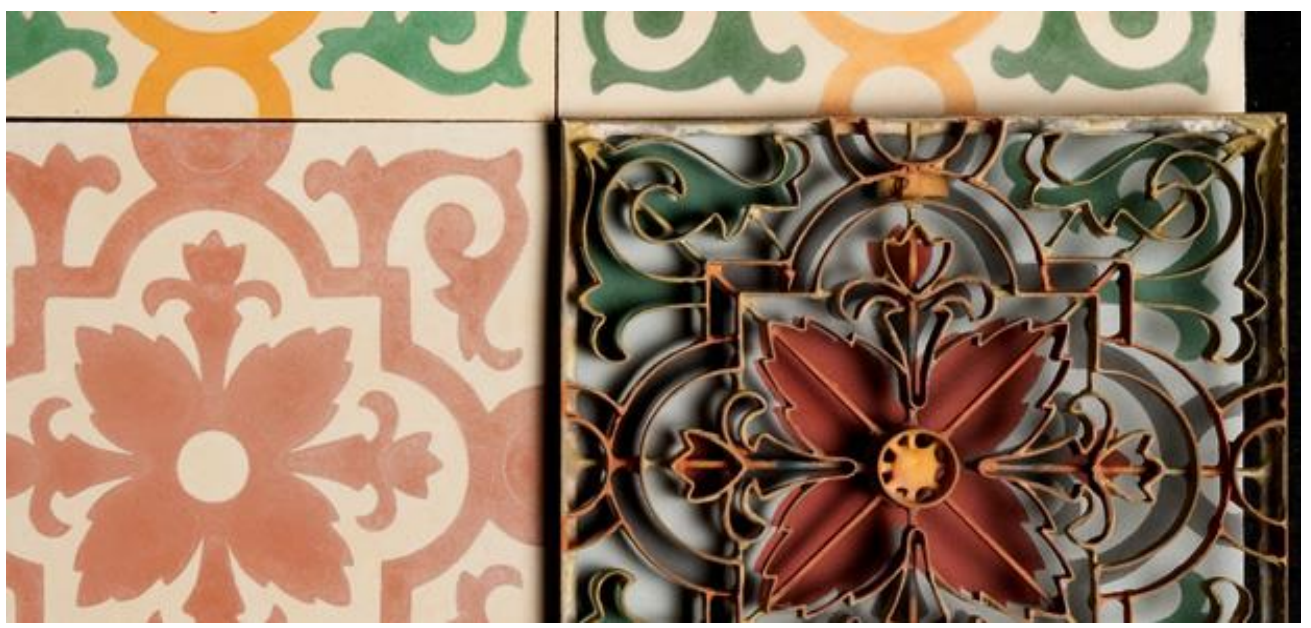

Fonte: Fonte: Ladrilhos hidráulicos Cerbras, 2012.

As cores são feitas com base em cimento e óxidos e são a primeira camada de três que constituem o ladrilho (Figura 3). A segunda camada consiste em uma mistura de cimento puro e areia que age como uma espécie de secante para a tinta. A terceira e última camada é, também, uma mistura de cimento e areia, mas que tem como função dar resistência ao ladrilho (AQUINO, 2018). Por fim, para que o desenho do ladrilho não se perca, ao invés de ser submetida à vibração, a peça é prensada para retirada de bolhas e depois de seca é mergulhada na água.

Figura 3 - Camadas do ladrilho hidráulico.

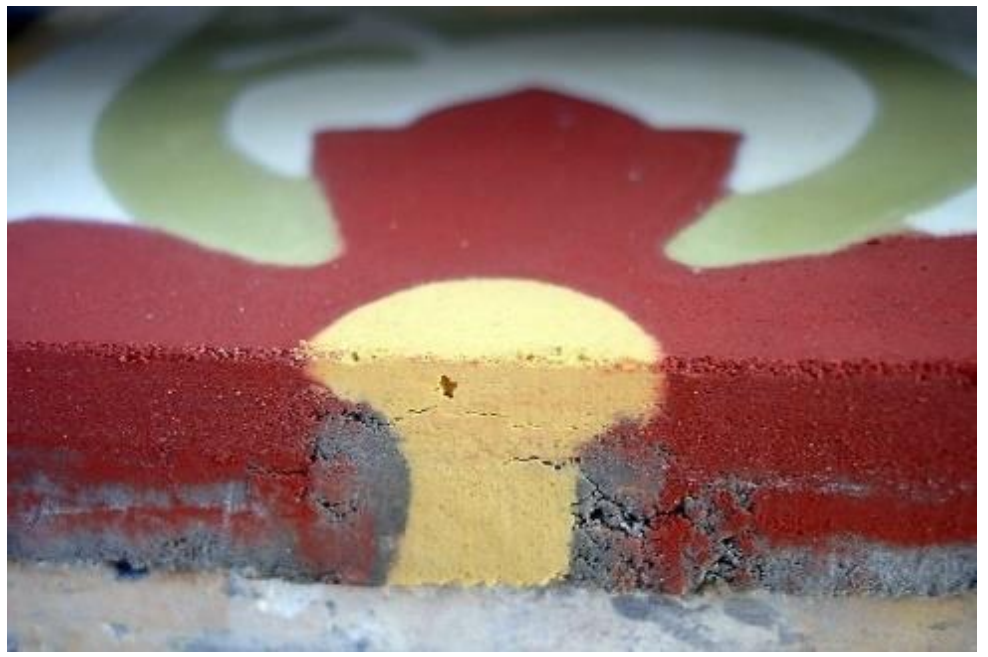

Fonte: O que é ladrilho hidráulico, 2014. 


\section{MERCADO}

O mercado do ladrilho hidráulico dos anos 90, até os dias atuais, se mostrou crescente, isso devido à procura dos arquitetos por este tipo de revestimento que possui características intimistas e uma produção artesanal que possibilita projetos únicos.

Essa demanda crescente pelas características dos ladrilhos hidráulicos demonstrou o aparecimento de novas fábricas de ladrilhos, como também uma tentativa de imitação do ladrilho por parte de outras fatias de mercado de revestimentos, como as fábricas de cerâmicas e vinílicos.

A substituição do ladrilho hidráulico no mercado, pelas cerâmicas, já ocorreu na década de 60. Década em que os revestimentos cerâmicos passaram a ser produzidos em grande escala e se tornaram uma opção mais barata na praça.

O crescimento do mercado das cerâmicas levou ao fechamento de muitas fábricas de ladrilhos causando o quase desaparecimento da cultura de produção do ladrilho hidráulico (informação verbal, de Mauro Galvão, fábrica Arte em Ladrilhos).

Considerando o grande interesse do mercado pelos ladrilhos e analisando os fatos ocorridos na década de 60 , é possível que novamente as cerâmicas suplantem os ladrilhos, o que poderia causar a perda dessa cultura imaterial de produção. Considerando os fatores de mercado de revestimentos, o preço de produção de um acabamento é fator muito importante na escolha entre uma ou outra opção. O ladrilho hidráulico, por suas características artesanais, chega à praça com um preço muito elevado e torna-se, muitas vezes, menos interessante do que as cerâmicas.

Para a preservação dessa cultura imaterial de produção é preciso repassar ao mercado que o seu significado é o elemento relevante em relação ao preço na hora da escolha de um produto. Com essas questões em voga, a orientação do ladrilho hidráulico para o mercado de joalheria se tornou uma possibilidade para transformar um output, que é o conhecimento da produção de ladrilho, para um input na produção de joias artísticas contemporâneas, transpondo a inovação e renovando a cultura com o Know-how técnico produtivo nesse mercado.

\section{JOALHERIA ARTÍSTICA CONTEMPORÂNEA}

Antes de transferir uma tecnologia de produção para outro mercado, foi preciso entender, por meio de outros projetos na área, se esse novo mercado já possuía trabalhos semelhantes que pudessem demonstrar a aceitação do público para esse projeto.

O que se verificou foi o crescimento do uso de novos e inusitados materiais na produção de joias. Esses projetos que fogem do uso de materiais nobres, como ouro e pedras preciosas, trabalham como ponto principal o significado e as possibilidades estéticas que materiais como sementes, cerâmicas e resinas proporcionam. Segundo OKAMOTTO (2008): "Por mais paradoxal que possa parecer, o galopante processo de globalização valorizou o fazer manual. 0 artesanato, hoje, é a contrapartida à massificação e à uniformização de produtos globalizados, promovendo ao mesmo tempo o resgate cultural e a identidade regional"

Dentre as pesquisas o cimento demonstrou-se uma opção crescente na produção de novas joias e bijuterias. Alguns exemplos de projetos que trabalham o cimento como forma de inovação na joalheria são os trabalhos da designer de joias brasileira, Silvia Blumberg e a designer israelense, 


\section{Hadas Shaham.}

Silvia trabalha o cimento em suas joias como forma de conscientização ambiental, no que ela coloca como forma de prestar atenção ao grande número de resíduos que a construção civil produz (BLUMBERG, 2017). Hadas Shaham trabalha o cimento junto com a prata trazendo elementos gráficos referentes a arquitetura de Israel. Ela utiliza o metal para produzir os grafismos e depois preenche os espaços com o cimento, incrustando a prata (SHAHAM, 2014), (Figura 4).

Figura 4 - (A) Pingente de cimento, Silvia Blumberg. (B) Pingente de cimento, Hadas Shaham.

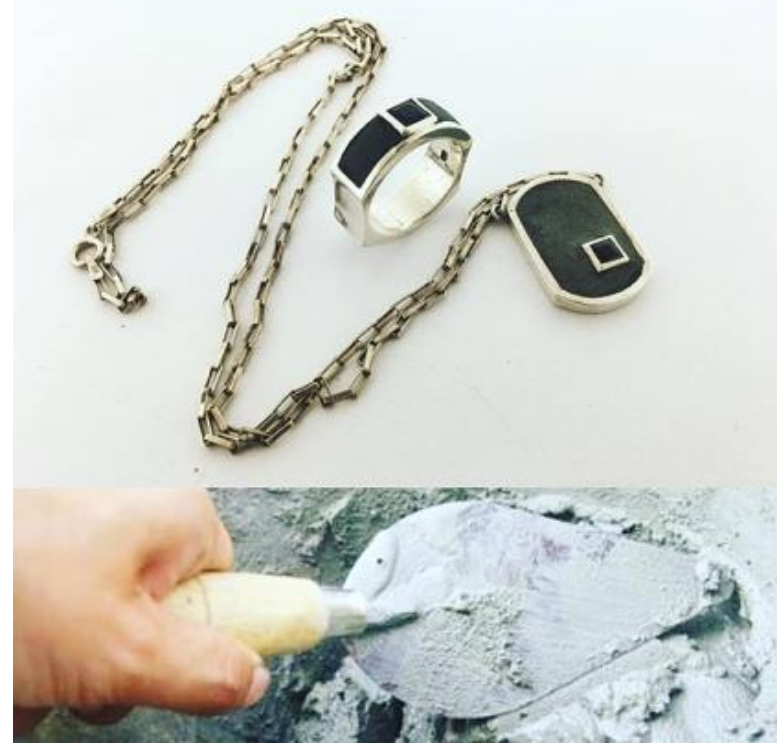

(A)

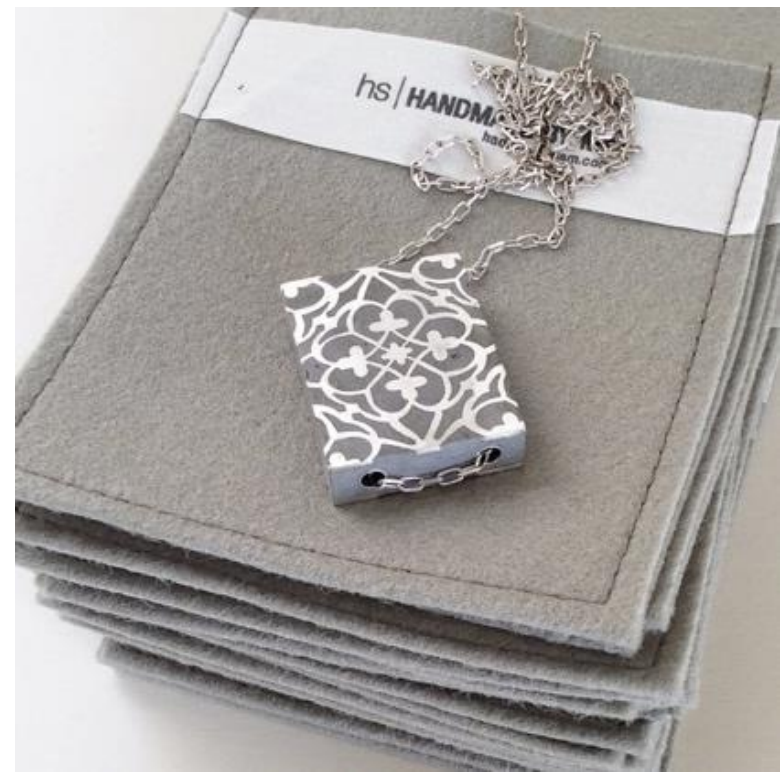

(B)

Fonte: (A) Foto de Silvia Blumberg, 2017; (B) Foto de Hadas Shaham, 2017.

\section{CENÁRIO E CONTEXTO}

Este trabalho teve como ponto de partida uma análise sistemática da produção artesanal do ladrilho hidráulico, enfatizando a produção da região mineira de Muriaé - MG e a tradicional fábrica produtora ARTE EM LADRILHOS, que há 90 anos produz ladrilhos hidráulicos na região Mineira.

De acordo com BISTAGNINO (2011) o método sistêmico coloca o homem e suas relações como ponto central do projeto, tornando assim as relações culturais, e a vida em sociedade como elementos importantes para serem perseguidos. Do ponto de vista desse processo metodológico a cadeia de produção não deve ser analisada dentro dela mesma, e sim através de suas relações e impactos, analisando os desdobramentos da cultura e do mercado. Essas relações entre a produção e os elementos externos de uma região são entendidas aqui como inputs e outputs do processo de produção, onde os inputs vão desde as matérias-primas necessárias à produção até o conhecimento empregado, e os outputs são todos os subprodutos causados, assim como toda expressão da sabedoria, das técnicas empregadas e por consequência a própria produção. 


\section{METODOLOGIA}

Para compreender os desdobramentos e as relações da produção do ladrilho hidráulico, assim como seus impactos socioculturais, econômicos e produtivos, tomou-se como processo de design o Método Sistêmico (BISTAGNINO, 2011) como abordagem metaprojetual, partindo da análise do território, do cenário local, e as relações existentes entre seus atores e sujeitos desse processo.

Com essa compreensão do problema é possível perceber que outputs causados por um processo podem se tornar a matéria-prima de um outro processo local, diminuindo os impactos da produção de um produto e também direcionando esse conhecimento para a promoção e preservação da cultura local através da transferência do know-how para outras atividades correlatas ou análogas. Analisado do ponto de vista sistêmico, não só a produção da fábrica ARTE EM LADRILHOS, mas também a própria história do ladrilho hidráulico, percebeu-se que, dentre os vários segmentos de output, um em particular, era a relação cultural e intimista a qual o ladrilho hidráulico estava ligado, determinando uma importância no processo que enfatizava o "saberfazer" e seus desdobramentos com legado sociocultural e econômico.

Para o desenvolvimento do projeto do produto, resultado desse estudo, foi utilizada a metodologia descrita por LÖBACH (2001), que propõe o processo nas seguintes etapas: Fase de preparação, fase de geração, fase de avaliação e fase de realização.

Para a fase de preparação foram colhidas informações referentes aos processos de produção dos ladrilhos hidráulicos e sua história. Com base nas informações obtidas foi possível fechar um briefing com as principais diretrizes, cujo o projeto deveria seguir, e o conceito para mediar as gerações de alternativas com relação aos aspectos semânticos que deveriam ser perseguidos.

$\mathrm{Na}$ fase de geração foram produzidos desenhos e modelos para expressar ideias com base nos parâmetros definidos, mas sem serem feitas grandes restrições de viabilidade a fim de não podar a criatividade nessa etapa.

Durante a fase de avaliação, foram selecionadas, com base em informações técnicas, as gerações que possuíam maior grau de viabilidade, e, também, foi apontado elementos técnicos que deveriam ser melhorados no que tangem questões de uso e produção.

Chegada a fase de realização foram utilizados conhecimentos técnicos para melhor identificar os processos que ajudariam na materialização da ideia selecionada na fase de avaliação, com o objetivo de chegar a um protótipo que pudesse demonstrar a factibilidade do produto desenvolvido.

\section{DEFINIÇÕES E PARÂMETROS DO PROJETO}

Depois das pesquisas realizadas foram definidos os parâmetros do projeto, que definem questões semânticas, de processo e de usabilidade quanto à passagem do ladrilho como revestimento para uma joia. 
Definiu-se que o processo do ladrilho hidráulico deve ser preservado por ser considerado um bem imaterial para a cultura, em consequência, as etapas e técnicas que caracterizam o processo do ladrilho devem ser respeitadas na produção de uma joia. Para isso as peças produzidas devem ser colorizadas com os seus respectivos óxidos exclusivamente com o cimento e feita em camadas.

Do ponto de vista semântico o ladrilho possui uma grande percepção como material usado na construção civil, como algo bruto e pesado. Essas são percepções que a joia feita em cimento não pode ter. As peças devem carregar a identificação intrínseca com o cimento, mas não se assemelharem com elementos típicos da construção, não devem ser semelhantes aos produtos da construção civil, elas também não podem ser mini reproduções de ladrilhos, pois iram carregar a conotação dos revestimentos usados e não como peças de adorno possíveis de serem usadas como joias e, principalmente, a valorização artística e cultural.

Na relação de usabilidade as peças devem ser confortáveis ao uso, do ponto de vista ergonômico, as peças em cimento não devem ferir, arranhar ou deflagrar qualquer possível incomodo ao usuário, além de serem fáceis de usar. Qualquer outro elemento de acabamento deve possuir qualidade suficiente para não causar alergias ou incômodos aos usuários.

Ainda com relação aos acabamentos, eles devem ser escolhidos de acordo com os aspectos de significados que serão definidos no conceito.

\section{O LADRILHO COMO JOIA CONTEMPORÂNEA}

O conceito definido para as joias de ladrilho hidráulico se baseia no sincretismo e ele inspira os elementos gráficos e formais das peças, influenciado pelo fato dos ladrilhos serem muito presentes em monumentos como igrejas e possuírem grande relação com o religioso considerando seus valores vindos dos mosaicos (Figura 5).

Figura 5 - Sincretismo Religioso, representações e culturas.

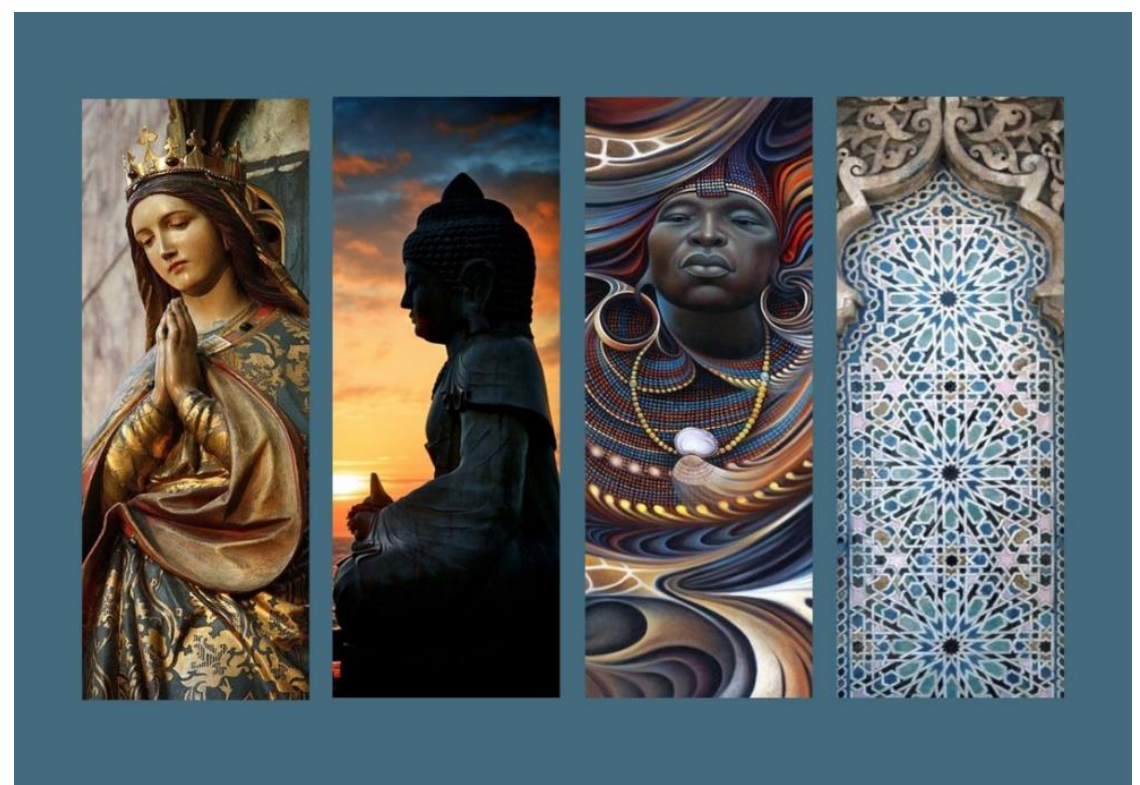

Fonte: Montagem ilustrativa do conceito determinada pelos autores, 2018. 
Sincretismo é a fusão de diferentes doutrinas para a formação de uma nova, seja de caráter filosófico, cultural ou religioso. O sincretismo mantém características típicas de todas as suas doutrinas-base, sejam rituais, superstições, processos e ideologias:

"Dentro das mais variadas culturas, o culto ao sobrenatural apresenta-se como fator de estabilidade social e de obediência às normas sociais. As religiões e as liturgias variam, mas o aspecto religioso é bem evidente. As pessoas procuram no misticismo e no sobrenatural algo que lhes transmita paz de espírito e segurança. Por isso a religião sempre desempenhou uma função social indispensável". (DE OLIVEIRA, 2002, p.169).

Até a segunda metade do século XIX não era complexa a definição do objeto joia. Segundo MERCALDI E MOURA (2017), o objeto joia estava atrelado ao valor implícito relacionado ao material no qual o artefato joia era materializado. Na atualidade a joia é analisada diante da sua preciosidade, no qual desafia a ideia de que o valor esteja simplesmente atrelado ao valor do material no qual é produzida, e desse modo, ao transformar a ideia convencional de valor, designers e joalheiros são convidados à experimentação expressando-se artisticamente, criativamente, enfatizando questões simbólicas e imateriais, transformando e inspirando o engajamento mais profundo com a sociedade e ao mesmo tempo propondo uma nova consciência de uso e de relações com o corpo:

"A mistura de técnicas e materiais de diferentes valores (tanto monetário quanto simbólico) tem sido cada vez mais comum. Um exemplo desta aceitação em relação à diversidade de materiais na joalheria é o Preview Design de Joias. Uma vez por ano o IBGM lança para os empresários do setor o Preview, um caderno que apresenta as tendências da moda na joalheria. Desde 2010 o caderno incorporou também a bijuteria como forma de estimular o mercado e a criatividade" (BENATTI e SILVA, 2012).

\section{DESENVOLVIMENTO}

Definidos os parâmetros e o conceito para uma coleção de peças de joalheria composta por anel, cordões e brincos, foram produzidos os desenhos das gerações de ideias e das gerações de alternativas para identificar as melhores relações em consonância com a proposta (Figura 6). 
Figura 6 - Síntese das gerações de Alternativas (A) e síntese das gerações de ideias (B).

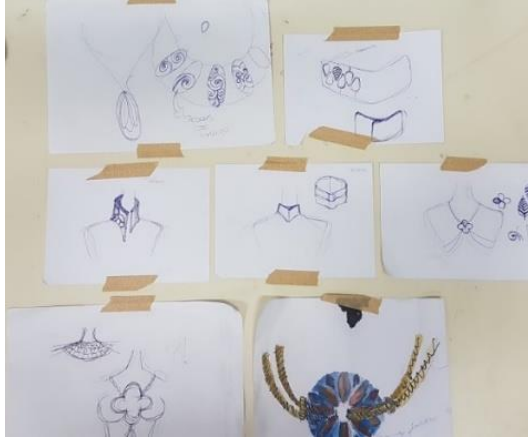

(A)

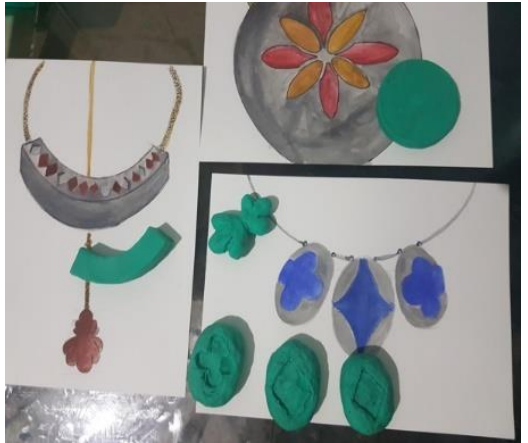

(B)

Fonte: Desenvolvimento projetual - DE OLIVEIRA, F.T.F., 2017.

No desenvolvimento demonstrado na Figura 6, os desenhos se focaram na forma de um maxi colar que seria a peça central da coleção, a partir dela seria feito o desdobramento para as outras peças, garantindo, assim, a unidade conceitual e visual da coleção. Depois de geradas as alternativas, foram feitas as seleções das peças que estavam de acordo com os parâmetros definidos e apresentavam a maior possibilidade de serem produzidas, considerando as limitações do material e do meio de produção. As peças selecionadas possibilitaram o uso de cores em camadas, e suas formas contribuíam para a resistência do cimento e contemporaneamente não traziam aspectos indesejáveis que as relacionariam formalmente com formas brutas do concreto ou miniaturizações de ladrilhos hidráulicos.

Foi optado por o desenvolvimento de três modelos no qual seriam submetidos a materialização. $O$ processo do ladrilho foi analisado a fim de perceber qual seria a melhor maneira para que os modelos fossem transferidos para o processamento. Depois dessa análise, um dos três modelos passou a ter continuidade, e assim foi feita a modelagem tridimensional assistida por computador, com o intuito de produzir um modelo mais fiel no qual poderia ser materializado por máquinas de prototipagem rápida no sistema CAM (Figura 7).

Figura 7 - Sistema de produção CAD e CAM. (A) Prototipagem; (B) Peças usinadas em Micro Fresadora.

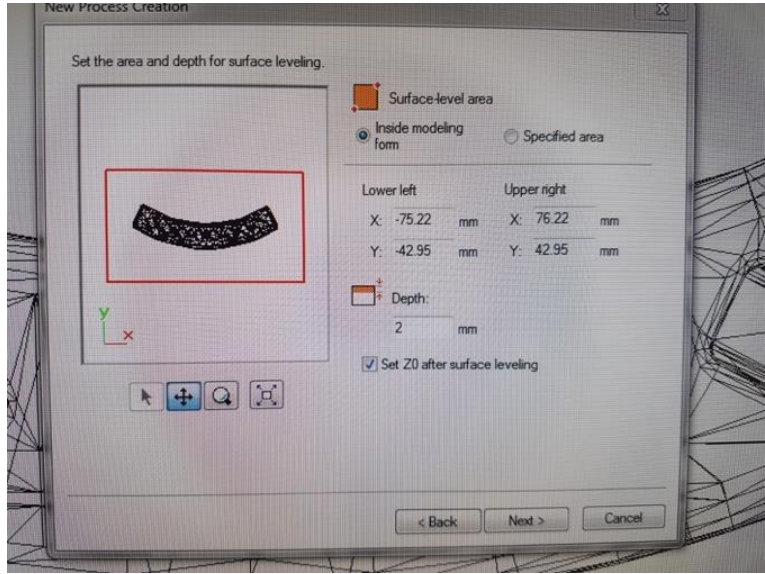

(A)

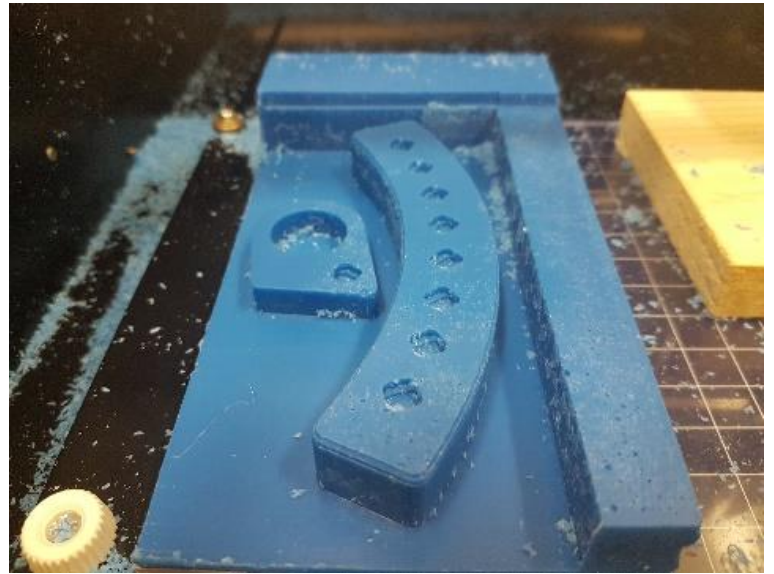

(B)

Fonte: Desenvolvimento projetual - DE OLIVEIRA, F.T.F., 2017. 
O processo de fabricação foi feito a partir dos modelos produzidos por CAM. Deles foram tirados moldes de silicone, que foram preenchidos com camadas de cimento colorido e cinza, garantindo assim a semelhança ao processo do ladrilho hidráulico (Figura 8).

Figura 8 - Sistema de produção manual. (A) Produção de moldes de silicone.; (B) Molde de silicone para produção de peça em cimento.

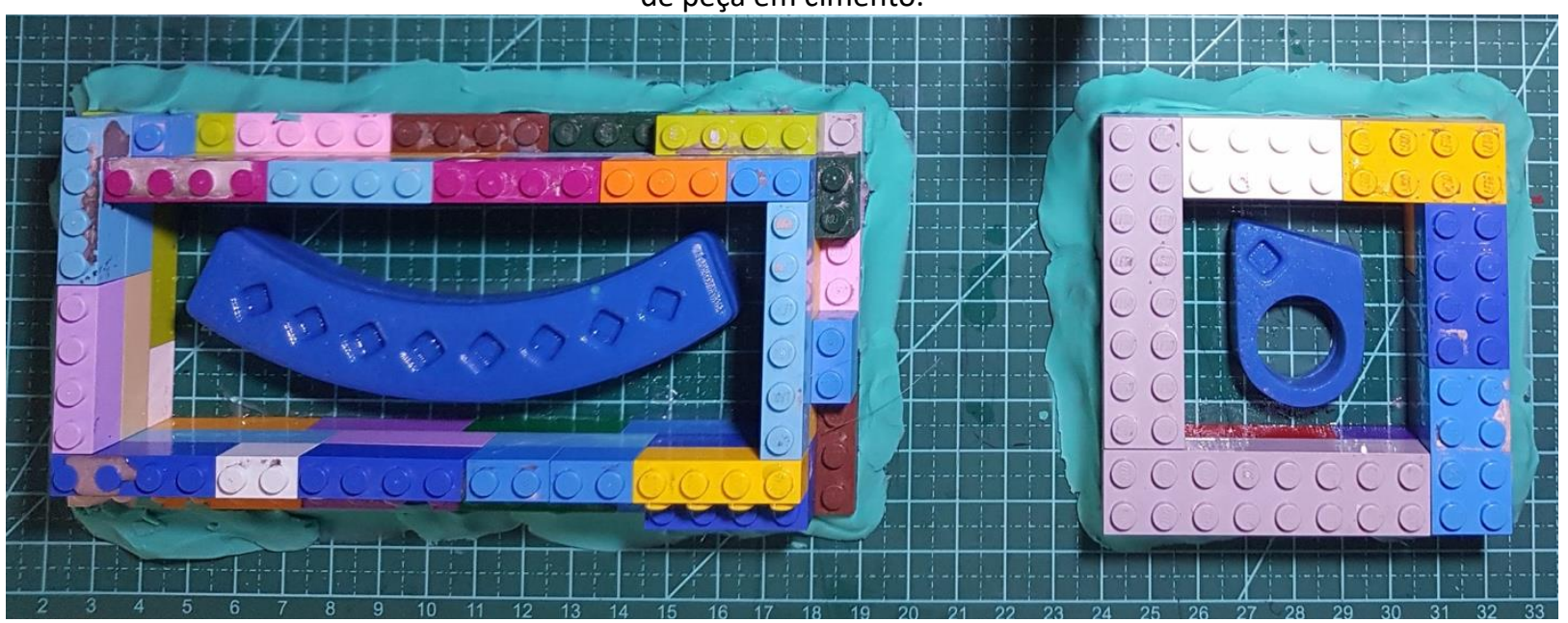

(A)

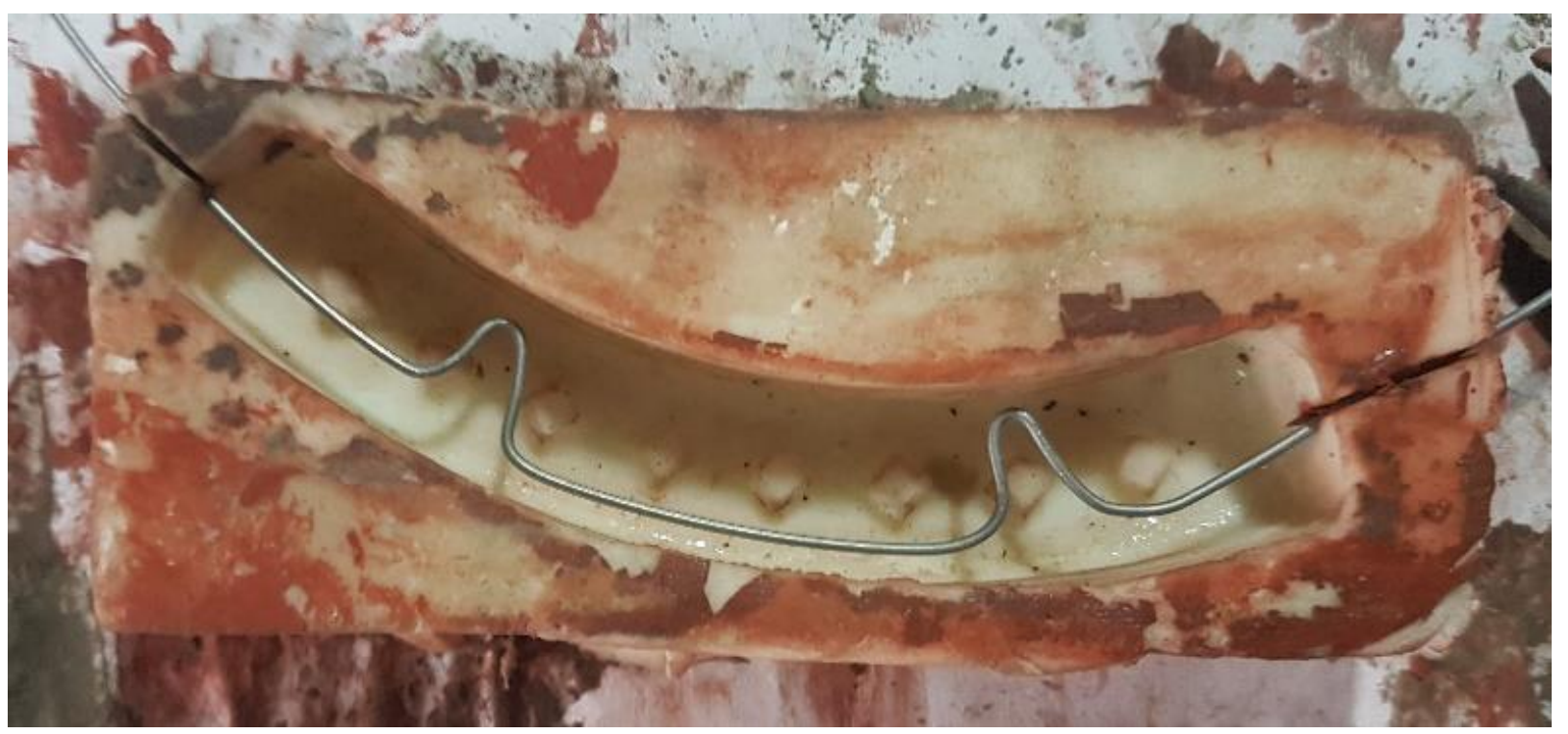

(B)

Fonte: Desenvolvimento projetual - DE OLIVEIRA, F.T.F., 2017. 


\section{RESULTADOS}

Após a finalização dos protótipos foi possível perceber as questões a serem melhoradas, a viabilidade e o sucesso do trabalho na passagem de um processo típico ao ladrilho, para um processo de produção de joias.

As peças foram produzidas com mistura de cimento, o que garantiu alta resistência, e um acabamento que proporciona proteção ao usuário. Os materiais de aviamentos como cordas e fechos foram selecionados com base no que se encontra no mercado, possuindo resistência a oxidação e aplicações de acordo com os aspectos do conceito do projeto (Figura 9).

Figura 9 - Peças confeccionadas. (A) Protótipo Maxi Colar; (B) Protótipo anel.

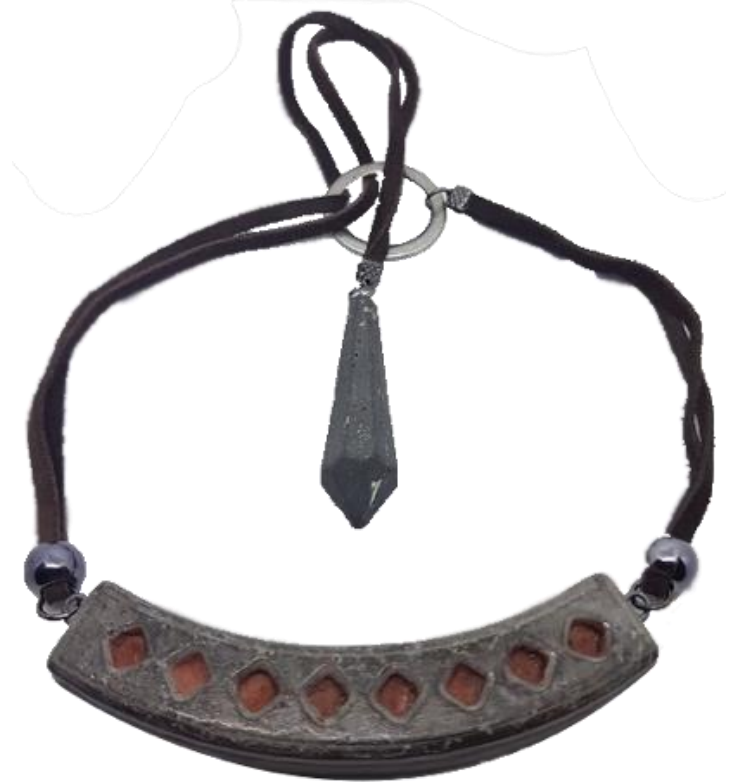

(A)

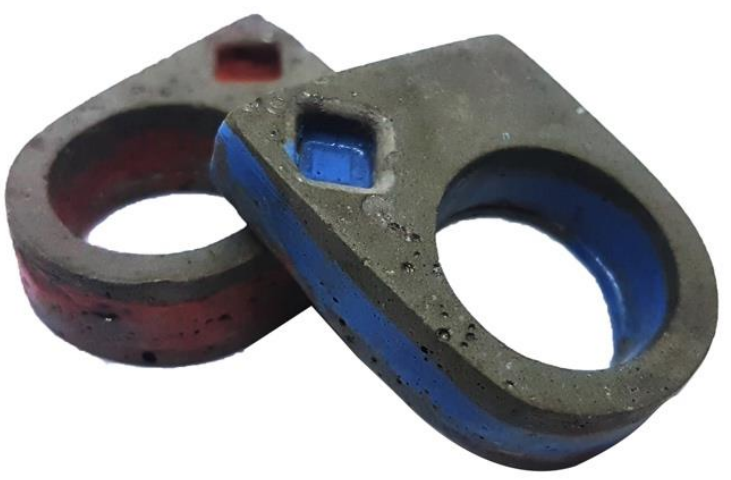

(B)

Fonte: Desenvolvimento projetual - DE OLIVEIRA, F.T.F., 2017.

Os produtos demonstraram atingir as expectativas de uso definidas no escopo da pesquisa, na definição de conceitos e no processamento dos materiais envolvidos típicos aos produtos de joias, garantido ao estudo a compatibilidade da passagem do universo inicial (ladrilho hidráulico) ao processo de joalheria artística.

- As peças não ficaram ásperas e também não soltam pó de cimento, por isso elas não machucam ou lixam os dedos ao serem colocadas. A superfície se mostrou extremamente lisa e pode ter opções de acabamento entre brilhoso, que é o aspecto de pedra lapidada, e o fosco.

- $O$ anel foi produzido integralmente em cimento possuindo um pequeno arame de aço inoxidável que permite a peça maior resistência. $O$ anel não causa incômodos e não atrapalham na movimentação normal dos gestos. 
- A resistência das peças atingiu um grau interessante e não é frágil a pequenas colisões, porém ainda possui o limite do próprio material de não resistir a quedas bruscas, ou muito altas.

- A aparência de bolhas e indefinição das camadas de cores são pontos, que serão definidas com o aumento da afinidade e melhora do processo.

- O processo desenvolvido no trabalho se mostrou viável, sem a necessidade de grandes investimentos em maquinários ou mão de obra especializada.

- Os objetivos traçados no briefing foram atingidos nos aspectos das etapas do processo, que são o cerne da produção de ladrilho, no que diz respeito ao uso de camadas de cimento cinza e colorido.

- A processo não leva a produção de mini ladrilhos, tornando as peças mais interessantes visualmente e mais distantes a conotação de produtos da área de construção.

- Toda a produção demandou moldes simples, acabamentos encontrados facilmente no mercado, e principalmente o cimento, que é material de fácil acesso.

\section{ASPECTOS CONCLUSIVOS}

Ao analisar os resultados do trabalho foi possível perceber a abertura de um novo cenário para a preservação de um método de produção que se tornou parte da cultura imaterial de uma região. O êxito na passagem de um conhecimento, como resultado de um processo de produção, para outro tipo de processo, demonstra o uso do design sistêmico na sustentação e na preservação no que tange as riquezas imateriais que constroem a identidade de uma região.

$\mathrm{O}$ ato de transformar e transportar um conhecimento para um outro seguimento de mercado, completamente diferente, é capaz de abrir um novo cenário para a exploração de um método de produção, como forma de preservá-lo, assim como foi demostrado no trabalho com a passagem da técnica do ladrilho hidráulico para a produção de joia, mercados que não concorrem entre si. Estes pontos demonstram que o pensamento de transposição de técnicas de um processo para o outro, pode criar e fortalecer a ideia de um sistema autopoiético, ou seja, que produz e recicla seus próprios componentes, nesse caso as suas próprias técnicas e Know-how.

Quanto ao uso de referências culturais para a produção da estética dos produtos, é possível concluir, a partir do projeto, que o significado de um produto pode superar os valores intrínsecos aos materiais. Com o atual cenário de globalização, aspectos de produções manuais, que valorizem e transmitem elementos de identidade locais, passaram a ser mais evidenciados e contemplados, possibilitando novas experimentações, assim, materiais e técnicas regionais podem alçar os valores das peças para além dos materiais com os quais elas foram produzidas. 


\section{REFERÊNCIAS BIBLIOGRÁFICAS}

AQUINO, J. Ladrilho Hidráulico - Saiba como fazer. Brasília: Ed. Kiron, 2018.

BENATTI, L. P. e SILVA, A. C. M. Influence of indigenous culture in the use of ornamental seeds as fashion accessories: how design can make the segment of biojewel more competitive. 1 st International Fashion and design congress. Guimarães: 2012.

BISTAGNINO, L. Design sistemico: Progettare la sostenibilità produttiva e ambientale. Bra, Slow Food, 2011. 310 p.

\section{BLUMBERG, S. Sustentabilidade.}

Disponível em: <http://silviablumberg.com.br/sustentabilidade/>. Acesso em: 4 set. 2017.

FARTHING, Stephen; CORK, Richard. Tudo sobre arte. Os movimentos e as obras mais importantes de todos os tempos. Rio de Janeiro: Ed. Sextante, 2011.

LÖBACH, B. Design industrial: bases para a configuração dos produtos Industriais. Ed. Blucher, 2001.

MERCALDI, Marlon Aparecido; MOURA, Mônica. Definições da joia contemporânea. Moda Palavra E-periódico, Ano 10, n.19, jan-jun 2017. ISSN 1982-615x

DE OLIVEIRA, Pérsio Santos. Introdução à sociologia. Ed Ática, São Paulo, SP, 2002.

OKAMOTTO, Paulo. Artesanato é negócio. Artesanato: um negócio genuinamente brasileiro. Sebrae, volume 1, número 1, março de 2008.

SHAHAM, H. Collections. Disponível em: <http://www.hadas-shaham.com/hs.html>. Acesso em: 4 set. 2017. 